\title{
INCIDENCE AND TREATMENT OF TRACHOMA IN PAKISTAN*
}

\author{
BY \\ M. ALIMUDDIN \\ Armed Forces Medical College, Rawalpindi, Pakistan
}

Trachoma is the cause of great human suffering in Pakistan, but no firm data of its incidence are available. Recently D.D.T. sprays and other antifly measures have assisted the prophylaxis of trachoma but have by no means lessened the importance of its treatment. The incidence of trachoma in Pakistan and the relative merits of various forms of therapy are discussed below.

\section{Geographical Situation of Pakistan}

The country consists of two wings-East Pakistan and West Pakistanseparated from each other by 1,500 miles of land. By far the greater part of the population (Table I) is concentrated in the relatively small area of East Pakistan in the delta formed by the Ganges and Brahmaputra rivers, which is the most densely populated part in the world and is conspicuous for its high rainfall (77 inches). The climate is humid, winters and summers are mild, and there are no sandstorms. In West Pakistan, which is divided into four provinces, mountain ranges run down the western borders, extending from the Himalayas to the sea, and the basin of the river Indus stretches out in wide plains from the foot of the mountains in the north. The mountainous area includes the North-West Frontier province and Baluchistan, and comprises much desolate, waterless, and sparsely populated country. In the plains lie the Punjab - the land of five rivers, a fertile agricultural area, and Sind, through which run the lower reaches of the Indus,

TABLE I

DISTRIBUTION OF POPULATION (CENSUS, 1951)

\begin{tabular}{|c|c|c|c|c|c|c|c|c|}
\hline \multirow{3}{*}{ Wing } & \multirow{2}{*}{\multicolumn{2}{|c|}{$\begin{array}{l}\text { Population } \\
\text { (millions) }\end{array}$}} & \multicolumn{4}{|c|}{$\begin{array}{c}\text { Sex Distribution } \\
\text { (millions) }\end{array}$} & \multirow{3}{*}{$\begin{array}{l}\text { Area } \\
\text { (thou- } \\
\text { sands } \\
\text { of sq. } \\
\text { miles) }\end{array}$} & \multirow{3}{*}{$\begin{array}{c}\text { Popu- } \\
\text { lation } \\
\text { (per sq. } \\
\text { mile) }\end{array}$} \\
\hline & & & \multicolumn{2}{|c|}{ Male } & \multicolumn{2}{|c|}{ Female } & & \\
\hline & No. & Per Cent. & No. & Per Cent. & No. & Per Cent. & & \\
\hline East Pakistan .. & 42 & 55 & 22 & 29 & 20 & 26 & $\frac{1}{7} \quad 54$ & 777 \\
\hline West Pakistan. . & 34 & 45 & 18 & 24 & 16 & 21 & $-\frac{6}{7} 312$ & 135 \\
\hline Total & 76 & 100 & 40 & 53 & 36 & 47 & 366 & 208 \\
\hline
\end{tabular}

* Received for publication March 12, 1957. 
where irrigation is steadily spreading its benefit into the once barren soil; this last province has little rainfall ( 7 inches), the climate is extreme both in winter and summer, and the atmosphere is dusty with frequent summer sandstorms (Fig. 1).

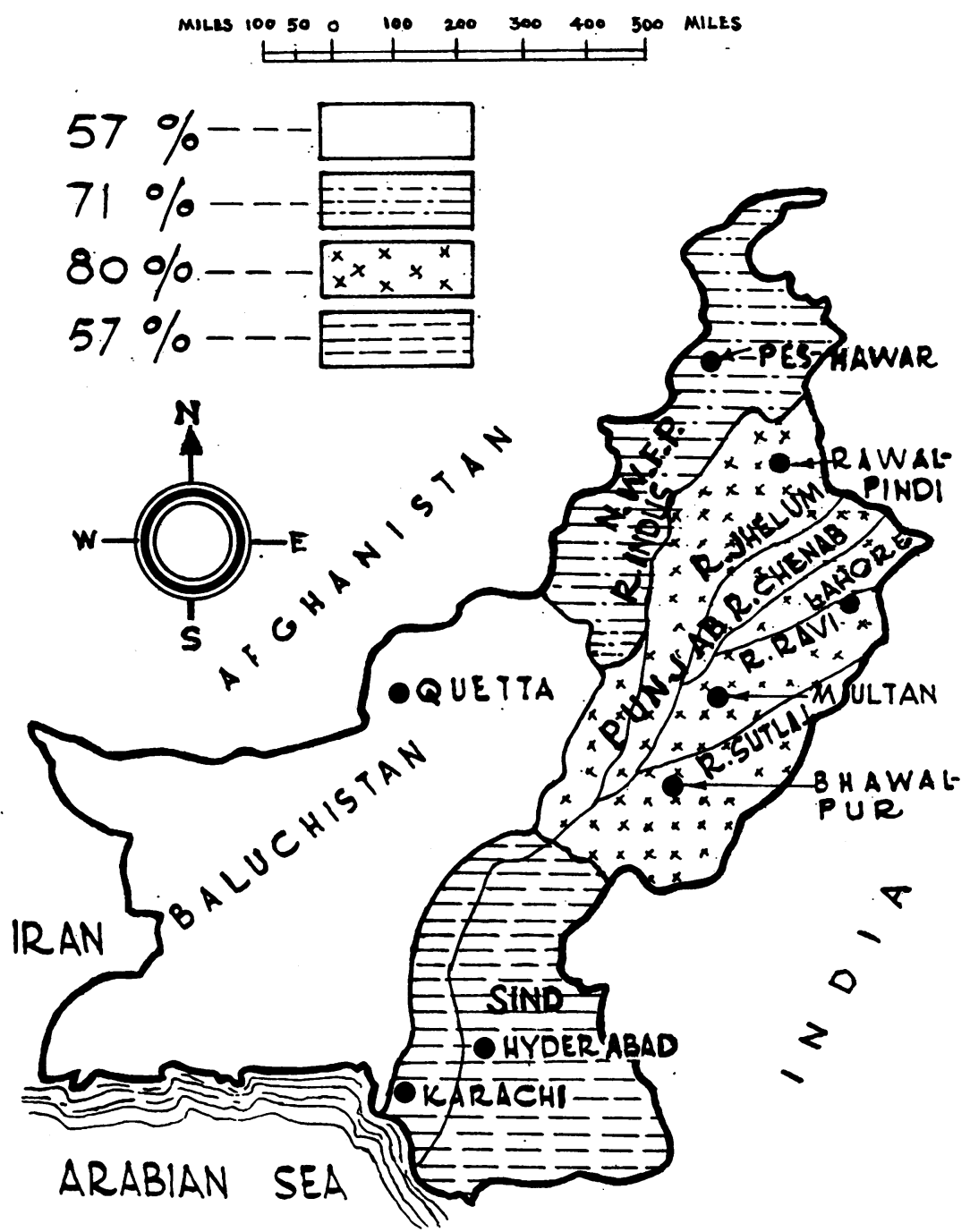

Fig. 1.-Map of the four provinces of West Pakistan.

\section{Incidence of Trachoma $\uparrow$}

Sample Examined.-It has not yet been possible to make a country-wide survey of trachoma, but the following method has been adopted where surveys have been made, and in this way a sample has been taken of the whole population. 
The hospital out-patients who attended the ophthalmological clinics from 1949 to 1955 were grouped by age, sex, and place of residence. They were examined for evidence of trachoma, active or quiescent, the complications of trachoma (such as ptosis, trichiasis, entropion, xerosis, corneal opacities, ulceration, etc.), and blindness due to trachoma. The numbers examined amounted to about one per thousand of the total population, except in East Pakistan, where it was about one per 1,400 (Table II).

TABLE II

INCIDENCE OF TRACHOMA

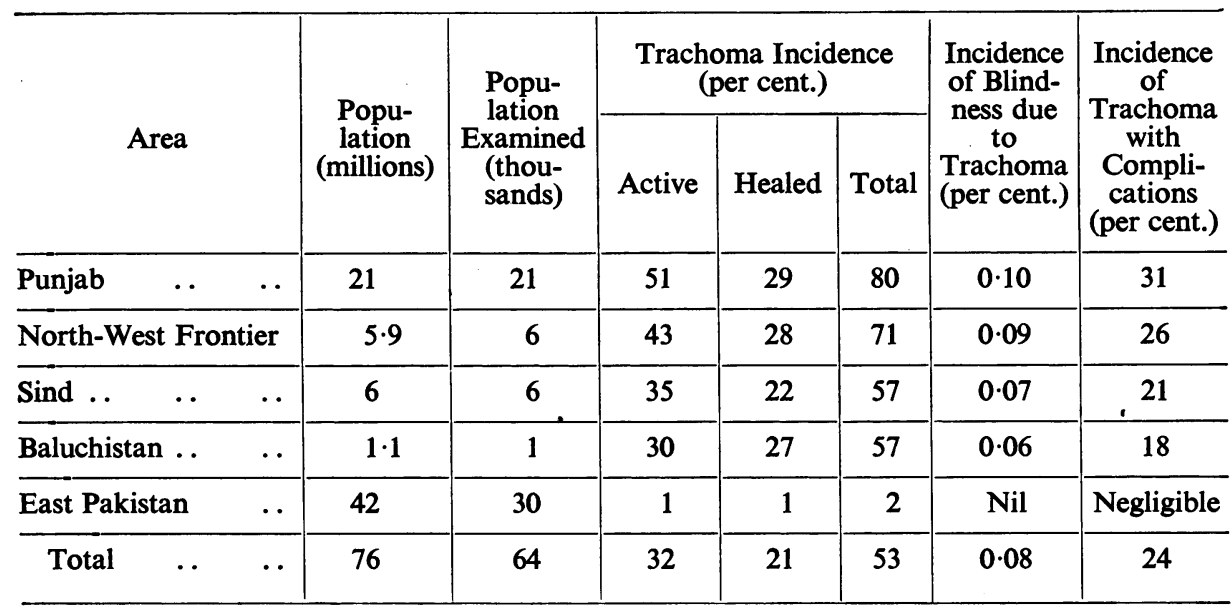

Results.-In nearly all cases both eyes were affected. There were many cases of trachoma in children as young as 2 years old, but the commonest age at onset of the disease was from 5 to 10 years.

The ratio of males to females was $1: 2$. The females suffered more severely both from the disease and from its complications. Attacks of trachomatous kerato-conjunctivitis increased during the hot season (April to July). The blinding effects of the disease were seen more often among the poorer classes of the populations. In all, 53 per cent. of the total population was found to be suffering from trachoma, active or healed (Table II), the worst-affected area being the Punjab, where the incidence was as high as 80 per cent., whereas in East Pakistan the incidence was as low as 2 per cent.

It is estimated that $0 \cdot 13$ per cent. of the population of Pakistan $(100,000$ individuals) are blind from all causes. Trachoma accounted for 0.08 per cent. (Table II), the remaining 0.05 per cent. being mainly due to uveitis, glaucoma, cataract, senile macular degeneration, and optic atrophy. Trachomatous complications, such as ptosis, trichiasis, entropion, xerosis, corneal opacities, and ulcerations, were seen in 24 per cent. of those examined. 


\section{Treatment}

Selection of Cases for Treatment.-Cases of Stage II trachoma (MacCallan, 1908) of the infiltrative or follicular type, showing corneal infiltration and pannus on slit-lamp microscopy and having similar clinical features and symptomatology, were selected for treatment.

Diagnosis.-Conjunctival scrapings were taken from the upper fornix with a sharp curette, after the instillation of cocaine and adrenaline drops, and were stained for one hour with 10 drops of freshly prepared Giemsa stain to $10 \mathrm{ml}$. distilled water to establish the presence of inclusion bodies. Intracellular inclusion bodies are characteristically seen in the early stages of trachoma, and therefore, because those selected were cases of fully-developed Stage II trachoma, inclusion bodies were found in only 12 per cent. The presence or absence of inclusion bodies was ignored in assessing diagnosis or cure.

The diagnosis was established by the presence of papillae or follicles (in vivo) evidente of infiltration, and pannus in the upper part of the cornea.

Therapy.-Each of the following methods of treatment was tried in twenty cases (Table III, overleaf). Ten further cases, used as controls to each group, were given normal saline drops only.

(i) 1 per cent. silver nitrate solution applied to the everted eyelids and fornices once daily for 7 days.

(ii) Copper sulphate crystals touched to the everted eyelids and fornices after cocainization once daily for 7 days.

(iii) Sulphacetamide 30 per cent. ointment six times daily for 6 weeks.

(iv) Chloramphenicol (Chloromycetin) as 1 per cent. ointment six times daily for 6 weeks.

(v) Chlortetracycline (Aureomycin) as 1 per cent. ointment six times daily for 6 weeks.

(vi) Oxytetracycline (Terramycin) as 1 per cent. ointment six times daily for 6 weeks.

(vii) Tetracycline (Achromycin) as 1 per cent. ointment six times daily for 6 weeks.

(viii) Curettage weekly and 1 per cent. Achromycin ointment six times daily for 6 weeks.

(ix) Combined curettage, Achromycin, and copper sulphate.

This was the same as (viii) above for 5 weeks followed by copper sulphate touched once a day and Achromycin ointment six times daily for the one remaining week.

Criteria of Cure.-Disappearance of symptoms; clearance of pannus and follicles; cicatrization of lid lesions; no relapse up to 6 months. A case was said to be cured only when this standard of recovery was achieved.

Results.-Silver nitrate for short periods was found to have little effect on trachoma, apart from clearing the secondary infection. Longer treatment 
TABLE III

EFFECTS OF DRUGS ON THE TREATMENT OF TRACHOMA

\begin{tabular}{|c|c|c|c|c|c|c|c|c|c|}
\hline \multirow{3}{*}{ Treatment } & \multirow{3}{*}{$\begin{array}{l}\text { No. of } \\
\text { Cases } \\
\text { Treated }\end{array}$} & \multicolumn{8}{|c|}{ Results } \\
\hline & & \multicolumn{2}{|c|}{$\begin{array}{c}\text { Clearance of } \\
\text { Secondary } \\
\text { Infection } \\
\text { within } \\
48 \mathrm{hrs}\end{array}$} & \multicolumn{2}{|c|}{$\begin{array}{l}\text { Clearance of } \\
\text { Pannus at } \\
\text { End of } \\
\text { Treatment }\end{array}$} & \multicolumn{2}{|c|}{$\begin{array}{l}\text { Relapse } \\
\text { (up to } \\
6 \text { mths) }\end{array}$} & \multicolumn{2}{|c|}{$\begin{array}{c}\text { Cured } \\
\text { (no relapse } \\
\text { up to } \\
6 \text { mths) }\end{array}$} \\
\hline & & No. & $\begin{array}{l}\text { Per } \\
\text { Cent. }\end{array}$ & No. & $\begin{array}{l}\text { Per } \\
\text { Cent. }\end{array}$ & No. & $\begin{array}{l}\text { Per } \\
\text { Cent. }\end{array}$ & No. & $\begin{array}{l}\text { Per } \\
\text { Cent. }\end{array}$ \\
\hline Silver Nitrate & 20 & 4 & 20 & Nil & Nil & 20 & 100 & Nil & Nil \\
\hline Copper Sulphate $\quad$. & 20 & 11 & 55 & 4 & 20 & 17 & 85 & 3 & 15 \\
\hline Sulphacetamide 30 per cent. & 20 & 18 & 90 & 12 & 60 & 16 & 80 & 4 & 20 \\
\hline Chloramphenicol .. & 20 & 16 & 80 & 6 & 30 & 16 & 80 & 4 & 20 \\
\hline Aureomycin & 20 & 17 & 85 & 7 & 35 & 15 & 75 . & 5 & 25 \\
\hline Terramycin .. & 20 & 16 & 80 & 5 & 25 & 17 & 85 & 3 & 15 \\
\hline Achromycin & 20 & 19 & 95 & 9 & 45 & 14 & 70 & 6 & 30 \\
\hline Curettage and Achromycin & 20 & 18 & 90 & 11 & 55 & 12 & 60 & 8 & 40 \\
\hline $\begin{array}{l}\text { Curettage, Achromycin, and } \\
\text { Copper Sulphate }\end{array}$ & 20 & 17 & 85 & 16 & 80 & 9 & 45 & 11 & 55 \\
\hline 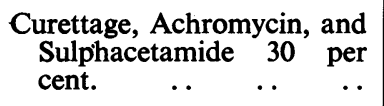 & 20 & 18 & 90 & 13 & 65 & 11 & 55 & 9 & 45 \\
\hline
\end{tabular}

was not tried for fear of argyrosis. During treatment there was apparent improvement clinically, but all cases relapsed within a short period of discontinuance of treatment.

Copper sulphate, the established "sheet-anchor" treatment of trachoma, was found to be of some value.

Of the antibiotics, Achromycin gave better results than the others, accounting for 30 per cent. of cures.

Combined treatment with curettage, Achromycin, and copper sulphate was the most efficacious, accounting for 55 per cent. of cures.

The controls to groups (i) and (ii) were treated for 7 days with normal saline, and the controls to group (iii) to (ix) were treated for 6 weeks. In general, not much improvement was noticed in the control cases; some improvement occurred spontaneously in a few cases, but the majority became worse during the 6-week period of observation, and specific treatment had to be started because of the deterioration of their clinical condition.

The systemic administration of antibiotics was found to have no advantage over topical application. Ointment was found to be better than drops, 
probably because it stays longer in the conjunctival sac and is not readily washed away by tears.

\section{Discussion}

Incidence.-A comparison of population densities in East and West Pakistan may appear misleading (Table I), because it may be thought that the population may be as dense in the cultivable areas of West Pakistan as it is in East Pakistan, but this is not so. In East Pakistan 55 per cent. of the total population occupies one-seventh of the total area of the whole country, and in West Pakistan the remaining 45 per cent. of the total population occupies about three-sevenths of the total area, the remaining three-sevenths being uninhabited and unproductive mountains and deserts (Slade, 1955). According to the Census of 1951, all the sixteen districts of East Pakistan have a population of over 500 persons per square mile (the actual average being 777), while only seven of the 46 districts of West Pakistan have a population of over 500 persons per square mile (the average being 135). The average populations of the four provinces of West Pakistan are shown in Fig. 2.

It is at first sight surprising that, in spite of this heavy overpopulation, the incidence of trachoma in East Pakistan is so low (1 to 2 per cent.), but this is probably caused by the following factors:

(a) Personal Hygiene.-East Pakistanis are particular about personal cleanliness; morning and evening baths are taken routinely even by lower classes of the population.

(b) Comparative Freedom from Insect Vectors.-Flies, ticks, and bugs are fewer than in West Pakistan.

(c) Heavy Rainfall.-East Pakistan is called the land of rivers and green vegetation, and the abundant rain (77 inches annually) cleanses the filth, dirt, and squalor.

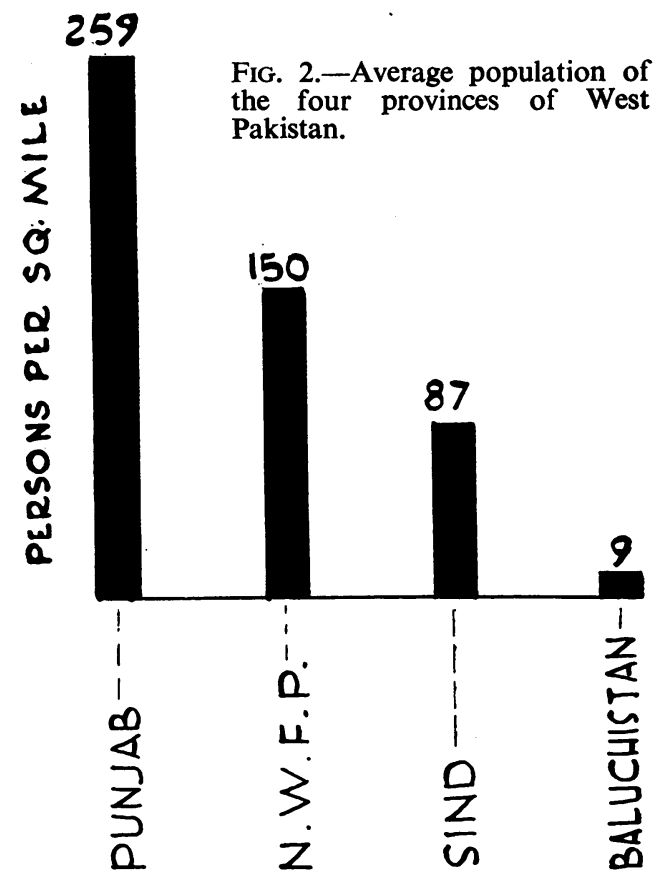

(d) High Humidity.-The humid climate with mild summers and winters appears to lower the endemicity of the disease; contiguous countries, like Burma, Siam, and Malaya, which have a climate similar to that of East Pakistan, also have a low incidence of trachoma.

(e) Rarity of Sandstorms.-The atmosphere is comparatively free from dust. 
In West Pakistan, on the other hand, 66 per cent. of the population were found to have active or healed stigmata of the disease, the Punjab being the most heavily affected area ( 80 per cent.), followed by the North-West Frontier, Sind, and Baluchistan, in that order (Table II). The dust, heat, drought, sandstorms, meagre rainfall, and extremes of climate, which may be called "ripening factors" for trachoma, all help to bring this about, and the higher incidence in the Punjab and North-West Frontier provinces may be ascribed to the denser population and to the fine, irritant sand particles which arise from the nature of the soil in these areas.

The incidence of trachoma in East Pakistan may rise because of the gradual increase in the interchange of population between East and West Pakistan.

Treatment.-Encouraging reports of the results of using sulphonamides and antiobiotics have appeared (Lavery, 1946; Duke-Elder, Ainslie, and Boase, 1950; Magnol, 1950; Naccache, 1953; Agarwal and Malik, 1955), but others found some of them of little value apart from clearing the secondary infection (Leopold, 1951; Shah, 1951; Siniscal, 1952).

In the series reported above, it has not been possible to assess the efficacy of these drugs on the trachoma virus because of the lack of facilities for virological studies, but the clinical results, as judged by the disappearance of symptoms, clearance of pannus and follicles, cicatrization of lid lesions, and absence of relapse up to 6 months, are encouraging.

\section{Summary}

The incidence of trachoma in East and West Pakistan and the efficacy of various antibiotics in its treatment are analysed. Achromycin 1 per cent. ointment with curettage and copper sulphate gave the best results.

My thanks are due to Lt.-Gen. W. A. Burki, C.B.E., Director General of Medical Services, and Maj.-Gen. M. N. Mahmood, Director of Medical Services, for their permission to publish these findings, and to Prof. M. Refatullah for supplying statistics for East Pakistan.

\section{REFERENCES}

Agarwal, L. P., and Malik, S. R. K. (1955). Brit. J. Ophthal., 39, 759.

DURE-ELDER, S., AINSLIE, D., and BOASE, A. J. (1950). Ibid., 34, 30.

LAVERY, F. S. (1946). Ibid., 30, 591.

LEOPOLD, I. H. (1951). A.M.A. Arch. Ophthal., 46, 177.

MacCallan, A. F. (1908). Ophthalmoscope, 6, 856, 947.

MAGNOL, F. (1950). Arch. Ophtal., 10, 636.

NACCACHE, R. (1953). Brit. J. Ophthal., 37, 106.

SHAH, M. A. (1951). Ibid., 35, 50.

SinisCal, A. A. (1952). Amer. J. Ophthal., 35, 671.

SLADE, E. H. (1955). Census of Pakistan, 1951, Vol. 1, Report and Tables, pp. 30-60. Government of Pakistan, Karachi. 